OPEN ACCESS

Edited by:

Luis Cláudio Nascimento da Silva,

Ceuma University, Brazil

Reviewed by:

Rodolfo García-Contreras,

National Autonomous University

of Mexico, Mexico

Henrietta Venter,

University of South Australia, Australia

*Correspondence: labal Ahmad ahmadiqbal8@yahoo.co.in

Specialty section:

This article was submitted to Antimicrobials, Resistance

and Chemotherapy,

a section of the journal

Frontiers in Microbiology

Received: 21 November 2016 Accepted: 07 April 2017

Published: 24 April 2017

Citation:

Husain FM, Ahmad I, Al-thubiani AS, Abulreesh HH, AlHazza IM and Aqil $F$ (2017) Leaf Extracts of Mangifera indica L. Inhibit Quorum Sensing Regulated Production of Virulence Factors and Biofilm in Test Bacteria. Front. Microbiol. 8:727. doi: 10.3389/fmicb.2017.00727

\section{Leaf Extracts of Mangifera indica L. Inhibit Quorum Sensing - Regulated Production of Virulence Factors and Biofilm in Test Bacteria}

\author{
Fohad M. Husain 1,2, Iqbal Ahmad1*, Abdullah S. Al-thubiani³, Hussein H. Abulreesh', \\ Ibrahim M. AlHazza ${ }^{4}$ and Farrukh Aqil ${ }^{5}$ \\ ${ }^{1}$ Department of Agricultural Microbiology, Faculty of Agricultural Sciences, Aligarh Muslim University, Aligarh, India, \\ ${ }^{2}$ Department of Food Science and Nutrition, College of Food and Agriculture Sciences, King Saud University, Riyadh, \\ Saudi Arabia, ${ }^{3}$ Department of Biology, Faculty of Applied Science, Umm Al-Qura University, Makkah, Saudi Arabia, \\ ${ }^{4}$ Department of Zoology, College of Science, King Saud University, Riyadh, Saudi Arabia, ${ }^{5}$ Department of Medicine and \\ James Graham Brown Cancer Center, University of Louisville, Louisville, KY, USA
}

Quorum sensing (QS) is a global gene regulatory mechanism in bacteria for various traits including virulence factors. Disabling QS system with anti-infective agent is considered as a potential strategy to prevent bacterial infection. Mangifera indica L. (mango) has been shown to possess various biological activities including anti-QS. This study investigates the efficacy of leaf extracts on QS-regulated virulence factors and biofilm formation in Gram negative pathogens. Mango leaf (ML) extract was tested for QS inhibition and QS-regulated virulence factors using various indicator strains. It was further correlated with the biofilm inhibition and confirmed by electron microscopy. Phytochemical analysis was carried out using ultra performance liquid chromatography (UPLC) and gas chromatography-mass spectrometry (GC-MS) analysis. In vitro evaluation of anti-QS activity of ML extracts against Chromobacterium violaceum revealed promising dose-dependent interference in violacein production, by methanol extract. QS inhibitory activity is also demonstrated by reduction in elastase (76\%), total protease $(56 \%)$, pyocyanin $(89 \%)$, chitinase $(55 \%)$, exopolysaccharide production $(58 \%)$ and swarming motility $(74 \%)$ in Pseudomonas aeruginosa PAO1 at $800 \mu \mathrm{g} / \mathrm{ml}$ concentration. Biofilm formation by P. aeruginosa PAO1 and Aeromonas hydrophila WAF38 was reduced considerably (36-82\%) over control. The inhibition of biofilm was also observed by scanning electron microscopy. Moreover, ML extracts significantly reduced mortality of Caenorhabditis elegans pre-infected with PAO1 at the tested concentration. Phytochemical analysis of active extracts revealed very high content of phenolics in methanol extract and a total of 14 compounds were detected by GC-MS and UPLC. These findings suggest that phytochemicals from the ML could provide bioactive anti-infective and needs further investigation to isolate and uncover their therapeutic efficacy.

Keywords: Mangifera indica, leaf extract, quorum sensing, biofilm inhibition, C. elegans, GC-MS, virulence factors 


\section{INTRODUCTION}

Development of multidrug resistance in bacterial pathogens has created special problem for antibiotic therapy (MacPherson et al., 2009). Therefore, new drug target identification and development of new therapeutics to combat bacterial infection is currently needed. The attenuation of virulence factors and pathogenicity of bacteria through interfering quorum sensing (QS) is a possible alternative to killing or inhibiting growth of pathogenic bacteria (Fuqua et al., 2001; Rumbaugh et al., 2012; Ghosh et al., 2014). Many researchers have indicated that QS which regulates the expression of many virulence traits in pathogenic bacteria as an attractive anti-infective drug target (Smith and Iglewski, 2003; Rasmussen and Givskov, 2006). Autoinducer (AI), diffusible signaling molecules, regulate QS which allow bacteria to change their behavior in population density-dependent manner (Williams, 2007; Dandekar et al., 2012). AIs used by Gram negative bacteria are mainly $\mathrm{N}$-Acyl homoserine lactones (AHLs) that play key roles in the virulence of pathogenic bacteria including Pseudomonas aeruginosa (Wang et al., 2009). P. aeruginosa, opportunistic pathogens, preferably infects the individuals with defective immune systems (Van Delden and Iglewski, 1998). The production of the majority of the virulence factors has been demonstrated to be regulated by one of the three QS systems, LasIR, RhlIR and PQS (McKnight et al., 2000; Smith and Iglewski, 2003; Jimenez et al., 2012).

Pseudomonas produces Las- and Rhl-dependent virulence factors and biofilm formation to facilitate the infection (Van Delden and Iglewski, 1998; Wang et al., 2009; Annapoorani et al., 2013). Bacterial biofilm development depends on release of extracellular polymeric compounds and QS mediated swimming and swarming motility (Pratt and Kolter, 1998; Jaisi et al., 2007). The bacteria in biofilm mode of growth become many fold tolerant to antibiotics than planktonic state of growth (Alhede et al., 2009). Biofilm formation inside the host resulted in successful establishment of pathogens and development of chronic infections in human (Annapoorani et al., 2013). The agents which obstruct bacterial QS and lead to the suppression of production of virulence factors are termed as QS inhibitors (Brackman et al., 2011). Such compounds were first reported in halogenated furanones of marine algae Delisea pulchra by Hentzer and Givskov (2003), but were found to be toxic and unstable.

Antibacterial activity of compounds from plants has been studied extensively. To obtain novel anti-QS agents, many workers have focused on natural products, because of the contribution in drug discovery. Recently, medicinal and food plants have been found to possess anti-QS property as reviewed by many workers (Musthafa et al., 2010; Husain and Ahmad, 2013b; Kalia, 2013; Zhao et al., 2013). Therefore, inhibition of QS has been envisioned to be the new target for developing anti-infective therapies because obstruction of QS will weaken the virulence of invading pathogens, making them more susceptible to the applied mode of treatment and facilitating easy clearance by host defense mechanism. However, discovery of therapeutically effective and safe anti-QS compounds is still in the stage of infancy and needs further exploration from natural products. In an ongoing screening program we have identified some potential anti-QS plants including Mangifera indica L.

Mangifera indica L. (Mango; family Anacardiaceae) has been shown to possess various medicinal properties (Shah et al., 2010). Polyphenolics, flavonoids and triterpenoids are the chief chemical constituents present in the plant. We have previously reported that leaf extract of $M$. indica demonstrated antibacterial, antifungal and antioxidant properties and we hypothesized that it may also be a potential source of anti-QS compounds. Therefore, in this manuscript we study the broad spectrum anti-QS and anti-biofilm properties of different fractions from ML extract against tester strains including Chromobacterium violaceum, P. aeruginosa $\mathrm{PAO} 1$ and Aeromonas hydrophila.

\section{MATERIALS AND METHODS}

\section{Bacterial Strains}

Chromobacterium violaceum (12472), produces QS-regulated purple-colored pigment, violacein. C. violaceum (CVO26) is a Tn5 mutant strain derived from wild-type C. violaceum (CV31532) and it is unable to produce its own AHL, but retain the ability to respond against exogenous butanoyl $\left(\mathrm{C}_{4}\right)$ and hexanoyl $\left(\mathrm{C}_{6}\right)$ homoserine lactones (McLean et al., 1997). $P$. aeruginosa $\mathrm{PAO}$ is a pathogenic bacterium having QScontrolled virulence factors. These cultures were kindly provided by Dr. Robert J. C. Mclean, Texas State University, San Marcos, TX, USA. Escherichia coli MG4/pKDT17 is E. coli DH5 $\alpha$ strain harboring plasmid pMG4/pKDT was kindly provided by Prof. Thomas K. Wood (Pennsylvania State University, USA). A. hydrophila WAF38 is an AHL producing our laboratory strain. C. violaceum 12472, C. violaceum CVO26, A. hydrophila WAF38 and $P$. aeruginosa PAO1 were maintained on Luria-Bertani (LB) broth at 28 and $37^{\circ} \mathrm{C}$, respectively.

\section{Plant Material and Preparation of Extracts}

Mangifera indica leaves were collected locally from the campus of Aligarh Muslim University, Aligarh, India. The mature dried leaves were finely ground and extract was prepared as described previously (Zahin et al., 2013, 2016). The extracts and fractions were dried by rotatory evaporator at $40^{\circ} \mathrm{C}$ followed by successive extraction of collected dried plant material with other solvents (benzene, ethyl acetate, acetone, methanol and ethanol). Each fraction was dried and store at $4^{\circ} \mathrm{C}$. The yield of each fraction was determined. DMSO (0.1\%) was used to reconstitute dry extracts for experimental purpose.

\section{Assay for Quorum Sensing Inhibition}

Inhibition of QS by plant extracts was analyzed as described (McLean et al., 2004). Briefly, test organism C. violaceum (ATCC $12472 ; 10^{6} \mathrm{CFU} / \mathrm{ml}$ ) was overlaid in $5 \mathrm{ml}$ soft agar on the agar plates. Wells of $8 \mathrm{~mm}$ were made and loaded with $100 \mu \mathrm{l}$ of solvent or plant extracts $(100-1000 \mu \mathrm{g} / \mathrm{ml})$. Fractions showing strong activity were repeated at lower concentrations using paper disk and tested by disk diffusion method. Inhibition of pigment 
production by the indicator strain around disk was considered as positive for QS interference. Similarly, assay was adopted with C. violaceum $\mathrm{CVO} 26$ with the addition of standardized $10 \mu \mathrm{M}$ of C6-HSL (Sigma-Aldrich, St. Louis, MO, USA).

\section{MIC Determination}

Broth dilution method was used to determine the minimum inhibitory concentration (MIC) of plant extracts. Tetrazolium salt ( $p$-iodonitrotetrazolium violet) was used as an indicator of growth as described earlier (Ahmad and Aqil, 2007).

\section{Violacein Inhibition Assay}

Production of violacein pigment by $C$. violaceum in the presence and absence of plant extract was analyzed by violacein extraction and quantified spectrophotometrically (Blosser and Gray, 2000). Briefly, 16-18 h $\left(\mathrm{OD}_{600 \mathrm{~nm}}=0.1\right)$ grown culture was incubated in Erlenmeyer flasks containing Luria broth supplemented with C6-HSL $(10 \mu \mathrm{M})$ in the absence and presence of plant extracts and incubated at $28^{\circ} \mathrm{C}$ for $24 \mathrm{~h}$. For quantification, bacterial cells were collected and the pellet was dissolved in $1 \mathrm{ml}$ DMSO. Cell debris was removed by centrifugation (13000 g; $10 \mathrm{~min}$ ) and absorbance of soluble violacein was read at $585 \mathrm{~nm}$ using microplate reader (Thermo Scientific, Multiskan Ex, India). Percent inhibition of violacein production in the presence of plant extracts was measured as, $\quad[(\mathrm{OD}$ of control $-\mathrm{OD}$ of treated $) / \mathrm{OD}$ of control $] \times 100$. Simultaneously, cell viability of CVO26 strain was determined. Bacterial viable count was made by agar plate count method.

\section{Analysis of Bacterial Growth Curve}

Effect of sub-MICs of ML extract on growth curve of PAO1 and WAF38 was determined. Bacterial culture was inoculated into LB broth $(100 \mathrm{ml})$ with and without the extract. The flask was incubated at $37^{\circ} \mathrm{C}$ for $24 \mathrm{~h}$. OD of the culture was monitored at $600 \mathrm{~nm}$ at interval of $2 \mathrm{~h}$ to plot the growth curve.

\section{Effect on Quorum Sensing Regulated Virulence Factors \\ Assay for LasB Elastolytic Activity}

The method described by Adonizio et al. (2008) was adopted to determine elastolytic activity. Bacterial culture was treated with plant extracts for $16 \mathrm{~h}$ at $37^{\circ} \mathrm{C}$. Both treated and untreated culture supernatant $(100 \mu \mathrm{L}$ each $)$ was mixed with $900 \mu$ l of elastin congo red (ECR) buffer (100 mM Tris, $\left.1 \mathrm{mM} \mathrm{CaCl}_{2}, \mathrm{pH} 7.5\right)$ containing $20 \mathrm{mg}$ of elastin congo red (ECR, Sigma, USA). This mixture was incubated at $37^{\circ} \mathrm{C}$ on shaker incubator for $3 \mathrm{~h}$ followed by removal of insoluble ECR by centrifugation. The absorption of the congo red was determined by reading the supernatant at $495 \mathrm{~nm}$ and LB medium with or without ML extract was included as negative control.

\section{Assay for Proteolytic Activity with Azocasein}

The method described by Kessler et al. (1993) was adopted to determine proteolytic activity of cell-free supernatants of test bacteria (PAO1 and WAF38) cultured with and without ML extract at sub-MICs. Briefly, culture supernatants $(150 \mu \mathrm{L}$ each) were added to $1 \mathrm{ml}$ of $0.3 \%$ azocasein (Sigma, USA) in $0.05 \mathrm{M}$ Tris- $\mathrm{HCl}$ and $0.5 \mathrm{mM} \mathrm{CaCl}_{2}$ ( $\mathrm{pH}$ 7.5) followed by incubation at $37^{\circ} \mathrm{C}$ for $15 \mathrm{~min}$. The reaction was stopped by adding the trichloroacetic acid $(10 \%, 0.5 \mathrm{ml})$. After centrifugation the absorbance was read at $400 \mathrm{~nm}$.

\section{Assay for Pyocyanin Production}

Method of Essar et al. (1990) was used to check the pyocyanin production. Briefly, culture supernatant $(5 \mathrm{ml})$ of $P$. aeruginosa (PAO1) treated with or without ML extracts was first extracted with chloroform $(3 \mathrm{ml}$ ) followed by re-extraction with $0.2 \mathrm{M} \mathrm{HCl}$ $(1 \mathrm{ml})$. The solution was assayed for absorbance at $520 \mathrm{~nm}$.

\section{Assay for Chitinase Activity}

Chitinase activity was measured as described previously (Husain et al., 2013) adopting a modified chitin azure assay. The filtersterilized culture supernatant was mixed in $2: 1$ with $0.1 \mathrm{M}$ sodium citrate buffer $(\mathrm{pH} 4.8)$, containing chitin azure $(0.5 \mathrm{mg} / \mathrm{ml})$ followed by incubation on a shaker for 1 week at $37^{\circ} \mathrm{C}$. The absorbance was recorded at $570 \mathrm{~nm}$.

\section{Swarming Motility Assay}

Swarming motility was determined as described earlier (Husain and Ahmad, 2013a). Briefly, the medium (1\% tryptone, $0.5 \%$ $\mathrm{NaCl}$ and $0.3 \%$ agar) with or without various Sub MIC concentration of ML extracts were point inoculated with the test cultures ( $P$. aeruginosa PAO1 and C. violaceum). After overnight incubation diameter of swarm was measured.

\section{Exopolysaccharide (EPS) Extraction and Estimation}

Bacterial strains PAO1 and WAF38 were cultivated in the presence of ML extract and subsequently centrifuged to obtain supernatant and filter sterilized. Chilled absolute ethanol was added in the supernatant and left overnight to precipitate EPS at $4^{\circ} \mathrm{C}$ (Huston et al., 2004). The method of Dubois et al. (1951) was used to estimate sugar concentration.

\section{Assay for Biofilm Inhibition}

The effect of ML at sub-MICs was determined using biofilm formation assay (O'Toole and Kolter, 1998). PAO1, WAF38 and CV 12472 cultures were grown overnight in the presence and absence of ML extract in microtitre plate. The biofilm was visualized after staining with crystal violet solution $(0.1 \%)$. After removing planktonic cells by rinsing the microtitre plate, the dye was solubilized in the ethanol and quantified spectrophotometrically at $470 \mathrm{~nm}$.

\section{In Situ Visualization of Biofilms}

Scanning electron microscopy (SEM) was done to visualize the biofilm in situ. The method described for biofilm formation on glass cover slip was adopted as described earlier (Husain et al., 2013). Briefly, biofilms were grown for $24 \mathrm{~h}$ on glass coverslips using 12 well plate with plant extract treated and untreated cultures of PAO1. Non-adhered cells from the cover slips were removed by rinsing with with distilled water and processed for SEM using standard protocol. 


\section{Effect on $\beta$-Galactosidase Activity}

Method of Harjai et al. (2010) was used to determine the $\beta$-galactosidase reporter activity. Supernatants of PAO1 treated with mango extracts were extracted with ethyl acetate for QS signal molecules (AHLs). Then, $0.5 \mathrm{ml}$ of ethyl acetate extract was incubated with $2 \mathrm{ml}$ of reporter E. coli MG4 (pKDT17) strain at $30^{\circ} \mathrm{C}$ for $5 \mathrm{~h}$ in shaker-incubator. Pellet was collected $(3200 \times g$ for $15 \mathrm{~min})$ and suspended in an equal volume of $\mathrm{Z}$ buffer $\left(\mathrm{Na}_{2} \mathrm{HPO}_{4}, 0.06 \mathrm{M}\right.$; $\mathrm{NaH}_{2} \mathrm{PO}_{4}, 0.04 \mathrm{M}$; $\mathrm{KCl}, 0.01 \mathrm{M} ; \mathrm{MgSO}_{4}, 0.001 \mathrm{M} ; \beta$-mercaptoethanol, $0.05 \mathrm{M}$; $\mathrm{pH}$ 7.0). To $1 \mathrm{ml}$ of cell suspension, $1 \mathrm{ml}$ of $\mathrm{Z}$ buffer, $200 \mu \mathrm{l}$ chloroform and $100 \mu \mathrm{l}$ of $0.1 \%$ SDS was added to lyse the cells, and $0.4 \mathrm{ml}$ of $\mathrm{O}$-nitrophenol- $\beta$-D-galactopyranoside (4 mg/ml in PBS) was added (Bhowmik and Marth, 1990). Reaction was stopped after the development of yellow color by adding $1 \mathrm{ml}$ of $1 \mathrm{M} \mathrm{Na}_{2} \mathrm{CO}_{3}$. Absorbance was measured at 420 and $550 \mathrm{~nm}$. Units of $\beta$-galactosidase were calculated as $\quad 1000 \times \mathrm{OD}_{420 \mathrm{~nm}}-\left(1.75 \times \mathrm{OD}_{550 \mathrm{~nm}}\right) /$ time $\times$ volume $\times$ $\mathrm{OD}_{600 \mathrm{~nm}}$.

\section{Effect on Caenorhabditis elegans Survival}

The method of Musthafa et al. (2012) was adopted to study in vivo efficiency of ML extract in Caenorhabditis elegans (C. elegans) nematode infection model. Briefly, the young adult nematodes were infected with PAO1 in the 24-well microtitre plate and incubated at $25^{\circ} \mathrm{C}$ for $12 \mathrm{~h}$. After incubation, C. elegans from the wells were washed thrice with $\mathrm{M} 9$ buffer $\left(\mathrm{KH}_{2} \mathrm{PO}_{4}, 3 \mathrm{~g}\right.$; $\mathrm{Na}_{2} \mathrm{HPO}_{4}, 6 \mathrm{~g} ; \mathrm{NaCl}, 5 \mathrm{~g} ; 1 \mathrm{M} \mathrm{MgSO} 4,1 \mathrm{ml}$; and distilled water $1000 \mathrm{ml}$ ) to remove surface-bound bacteria. Around 10 infected worms were transferred to the wells of microtitre plate containing $10 \% \mathrm{LB}$ broth in M9 buffer and incubated at $25^{\circ} \mathrm{C}$ with or without plant extract.

\section{Determination of Total Phenolic of Plant Extract}

The total phenolic content of the ML extract was assayed by the method of Spanos and Wrolstad (1990), as described earlier (Zahin et al., 2010).

\section{Gas Chromatography-Mass Spectrometry (GC-MS) Analysis of Plant Extracts}

The compositions of the ML extract was analyzed by gas chromatography as described earlier by Zahin et al. (2016).

\section{Ultra Performance Liquid Chromatography (UPLC) Analysis}

The method describe earlier by Aqil et al. (2014) was adapted with little modification. Briefly, methanolic extracts of MLwas analyzed for the phenolics on a Shimadzu ultra performance liquid chromatography (UPLC) system comprised of two LC20AD-XR pumps, SIL-20A-XR autosampler, and SPD-M20A photodiode array detector (PDA) controlled by Class VP software (ver 7.4, SP3) attached to a Shim-pack XR-ODS-II column
(3.0 $\mathrm{mm} \times 150 \mathrm{~mm} ; 2.2 \mu)$. A linear gradient of $3.5 \%$ phosphoric acid (solvent $\mathrm{A}$ ) and acetonitrile (solvent $\mathrm{B}$ ) with flow rate of $0.7 \mathrm{ml} / \mathrm{min}$ was used. In the gradient, solvent B was initially $15 \%$ for $2 \mathrm{~min}$ and increased to $20 \%$ by $3 \mathrm{~min}$. The solvent $\mathrm{B}$ concentration was further increased to $60 \%$ from 3 to $10 \mathrm{~min}$ and held for $1 \mathrm{~min}$ and returned to $15 \%$ by $14 \mathrm{~min}$. The chromatogram was collected from 200 to $600 \mathrm{~nm}$ and general phenolics were analyzed at $280 \mathrm{~nm}$.

\section{Statistical Analysis}

All experiments were performed in triplicate and the data obtained from the experiments were presented as mean values with or without standard deviation and the differences between control and test were analyzed using Student's $t$-test.

\section{RESULTS}

Different extracts of ML were obtained in petroleum ether, benzene, ethyl acetate, acetone and methanol and tested for QS modulatory activity against C. violaceum (CV12472). The methanol fraction showed dose-dependent anti-QS activity being best effective without any growth inhibition at $400 \mu \mathrm{g} / \mathrm{ml}$ concentration (Table 1). At higher concentrations pigment inhibition, a determinant of anti-QS activity was accompanied by growth inhibition of CV12472. The ethyl acetate fraction also exhibited anti-QS activity but only at $1800 \mu \mathrm{g} / \mathrm{ml}$ concentration. Acetone fraction inhibited pigments at 400 and $800 \mu \mathrm{g} / \mathrm{ml}$; however, it also inhibited bacterial growth at the same concentration. Petrol and benzene fractions showed no inhibition of QS at tested concentrations $(200-1600 \mu \mathrm{g} / \mathrm{ml})$. To assess the effect of ML fractions on QS-regulated functions MIC was determined. The MIC of the extract against CVO26 was $1000 \mu \mathrm{g} / \mathrm{ml}$, and against $P$. aeruginosa PAO1 and A. hydrophila WAF38, the MIC was $2000 \mu \mathrm{g} / \mathrm{ml}$.

\section{Effects of ML Extract on QS-Regulated Virulence Factors/Traits}

The methanol fraction demonstrated dose-dependent interference in QS activity as shown by reduced violacein production in CVO26 supplemented with synthetic AHL. It almost completely reduced the violacein production upto $83.6 \%$ at the concentration of $800 \mu \mathrm{g} / \mathrm{ml}$. The effect was significant even at 400,200 , and $100 \mu \mathrm{g} / \mathrm{ml}$ concentrations with 55.6, 32.1, and $8.2 \%$ reductions, respectively (Figures $\mathbf{1 A}, \mathbf{B}$ ).

Table 2 shows the dose-dependent effect of plant extracts on virulence factors in PAO1. Elastase activity decreased substantially at sub-inhibitory concentrations $(100-800 \mu \mathrm{g} / \mathrm{ml})$ of mango leaf (ML) extract with $17.6-76.2 \%$ reduction compared to the control. Similarly, a significant concentration-dependent decrease (43.8-56\%) of total protease production was observed in the culture supernatant of $P$. aeruginosa at $200-800 \mu \mathrm{g} / \mathrm{ml}$ extract. Pre-treatment with extract $(100,200,400$, and $800 \mu \mathrm{g} / \mathrm{ml})$ caused significant reduction of pyocyanin pigment $(69.7,80.2$, 85.6 , and $88.8 \%$, respectively) in a dose-dependent manner (Table 2). Chitinase activity also decreased with ML extract but this decrease was significant (55.3\%) only at $800 \mu \mathrm{g} / \mathrm{ml}$ conc. 
TABLE 1 | Inhibition of C. violaceum (CV12472) pigments by different fractions of Mangifera indica.

\begin{tabular}{|c|c|c|c|c|}
\hline \multirow[t]{2}{*}{ Fractions } & \multirow[t]{2}{*}{ Concentration $(\mu \mathrm{g} / \mathrm{ml})$} & \multicolumn{3}{|c|}{ Zone of inhibition (mm) } \\
\hline & & Total inhibition $\left(r_{1}\right)$ & Growth inhibition $\left(r_{2}\right)$ & Pigment inhibition $\left(r_{1}-r_{2}\right)$ \\
\hline \multirow[t]{4}{*}{ Ethyl acetate } & 225 & - & - & - \\
\hline & 450 & - & - & - \\
\hline & 900 & - & - & - \\
\hline & 1800 & 5 & - & 5 \\
\hline \multirow[t]{4}{*}{ Acetone } & 100 & - & - & - \\
\hline & 200 & - & - & - \\
\hline & 400 & 18 & 15 & 3 \\
\hline & 800 & 21 & 16 & 5 \\
\hline \multirow[t]{4}{*}{ Methanol } & 200 & - & - & - \\
\hline & 400 & 15 & - & 15 \\
\hline & 800 & 21 & 2 & 19 \\
\hline & 1600 & 25 & 8 & 17 \\
\hline
\end{tabular}

Data are the mean value of three replicate. Values are round off to nearest whole number. Petroleum ether and benzene fractions do not show any activity; -, No activity. Total inhibition = total zone of pigment inhibition including growth inhibition, if any.

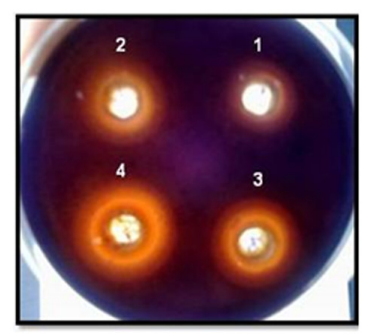

B

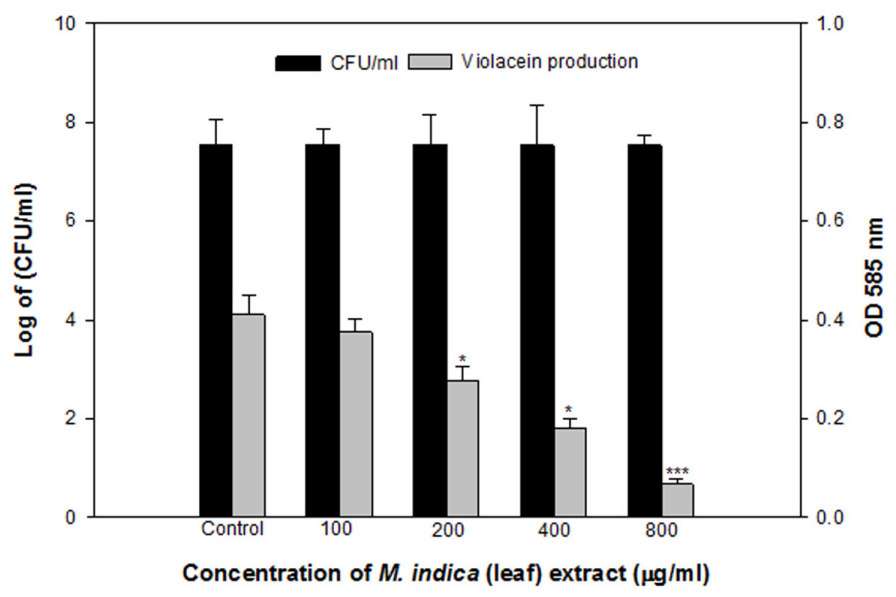

FIGURE 1 | (A) Inhibition of violacein by methanol extract of Mangifera indica (leaf) in C. violaceum at the concentration of 200 (1), 400 (2), 800 (3), and 1600 (4) $\mu \mathrm{g} / \mathrm{ml}$. (B) Quantitative assessment of violacein inhibition in CVO26 at sub-inhibitory concentrations of $M$. indica (leaf) extract. All of the data are presented as mean \pm standard deviation. ${ }^{*} p \leq 0.05,{ }^{* * *} p \leq 0.001$.

Similarly, a concentration-dependent decrease in the production of EPS was recorded in the treated culture of PAO1 compared to control. The extract exhibited statistically significant reduction of 50.2 and $58.3 \%$ in EPS at 400 and $800 \mu \mathrm{g} / \mathrm{ml}$, respectively. In the present study, ML extract significantly reduced flagella-mediated swarming motility of $P$. aeruginosa PAO1 (25.2-73.7\%) at tested sub-MICs (Table 2 and Figure 3).

Effect of the methanol extract on virulence factors of A. hydrophila WAF38 is represented in Table 3. The extract demonstrated significant reduction in total protease activity (54-69\%). EPS production in WAF38 strain was also reduced in a dose-dependent manner and significant decrease of 41.9, 52.2 , and $59 \%$ was observed at 250, 500, and $1000 \mu \mathrm{g} / \mathrm{ml}$ concentration of the extract. Growth curve analysis showed that sub-MICs of $M$. indica did not cause significant change in the growth of $P$. aeruginosa PAO1 and A. hydrophila (Supplementary Figure S1)

\section{Effect on Biofilm Formation}

Sub-MICs were tested for biofilm inhibition in $P$. aeruginosa (PAO1) using crystal violet assay. Biofilm formation was significantly inhibited by 48,56 , and $72 \%$ at 200,400 , and $800 \mu \mathrm{g} / \mathrm{ml}$ concentrations, respectively (Table 2). SEM images also revealed reduction in the biofilm formation when treated with extracts (Figure 2). The impact of ML extract on WAF38 biofilm formation was also studied and a maximum reduction of $82.3 \%$ at $1000 \mu \mathrm{g} / \mathrm{ml}$ was recorded. At lower concentrations, there was also significant reduction in the range of $56-76 \%$ (Table 3).

\section{Effect on $\beta$-Galactosidase Activity}

The las-controlled transmission was determined by inhibition of $\beta$-galactosidase activity. Mango extract at $800 \mu \mathrm{g} / \mathrm{ml}$ showed reduction in $\beta$-galactosidase in $E$. coli MG4/pKDT17 by $64 \%$ (Figure 4), suggesting direct inhibition of las-controlled 


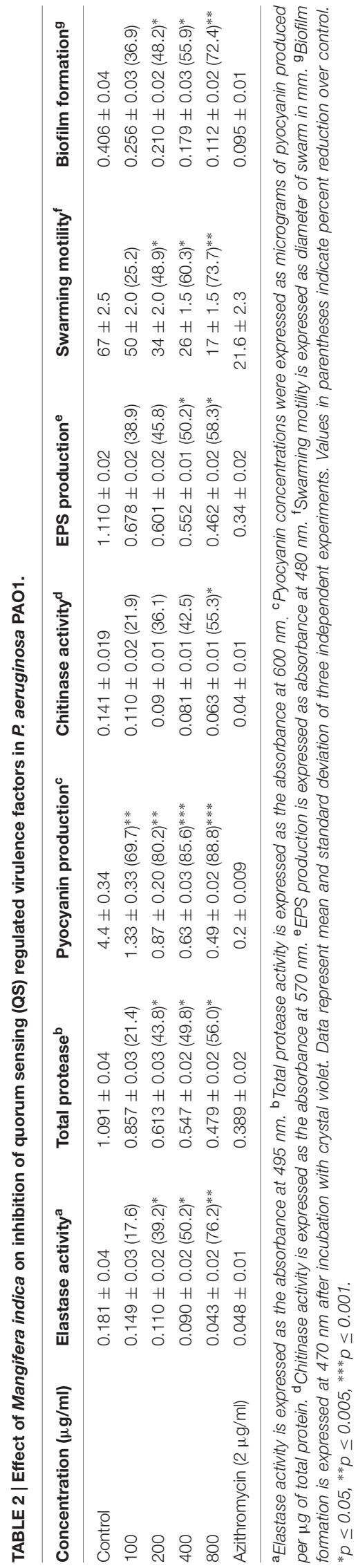

transcription by ML bioactives. The effect was also significant at 200 and $400 \mu \mathrm{g} / \mathrm{ml}$ concentration.

\section{Anti-infective Potential of Plant Extracts in C. elegans Nematode Model}

In this model, $C$. elegans was infected with $P$. aeruginosa followed by treatment with ML extract. In the absence of extracts, $100 \%$ mortality of C. elegans was recorded after $72 \mathrm{~h}$ demonstrating the PAO1 pathogenicity. On the other hand, C. elegans pre-infected with $\mathrm{PAO} 1$ and maintained in the presence of $\mathrm{ML}$ extract $(800 \mu \mathrm{g} / \mathrm{ml})$ displayed an enhanced survival rate of $72 \%$ (Figure 5). The ML extracts could not exhibit significant mortality of C. elegans at the tested concentration.

\section{Phytochemical Analysis of Leaf Extract}

The total phenolic content (mg GAE/g) of extract was assayed by the Folin-Ciocalteu method and 497.6 gallic acid equivalents $(\mathrm{mg} / \mathrm{g})$ was recorded. Gas chromatography-mass spectrometry (GC-MS) analysis revealed 16 components in methanol fraction using a direct similarity search. The major compounds identified were pyrogallol (15.6\%), benzoic acid, 4-hydroxy (12.09\%), n-hexadecanoic acid (9.96\%), 4H-pyran-4-one, 2,3-dihydro-3,5dihydroxy-6-methyl (8.48\%) as evident from the GC-MS spectra (Table 4 and Supplementary Figures S2, S3). It is possible to extend the number of phytoconstiuents using chemometric techniques. We further analyzed the active methanolic fraction of ML with UPLC (Figure 6). The UPLC analysis revealed the presence of 7-8 major phytocompounds at different wavelength and distinct time of retention. The retention time of compounds was found between 6 and $13 \mathrm{~min}$. The spectral analysis of major peaks revealed highest absorbance at around $270 \mathrm{~nm}$ suggesting their identity as phenolics. However, these peaks remained to be identified.

\section{DISCUSSION}

In many bacteria virulence factors are regulated through QS, a cell density-dependent global gene regulatory mechanism. Interference of QS circuits is considered as potential strategy to attenuate bacterial pathogenecity. In an ongoing program we have identified some potential plants with anti-QS activity in preliminary screening including $M$. indica L. (Zahin et al., 2010). In this study ML extract is subjected to sequential fractionation in different organic solvents and tested for QS interference by reduction in violacein production in C. violaceum 12472 . Violacein production by C. violaceum is regulated by CviIRdependent QS system (McLean et al., 2004). Therefore, any modulation of pigment in C. violaceum is considered direct evidence of QS interference.

The methanol fraction of ML apparently reduced the AHL-dependent pigment production, indicating interference of QS-controlled function. Further, interference of QS by the methanol fraction is also evident as it inhibited the violacein production in CVO26 without interfering the growth of C. violaceum. A similar effect on the violacein inhibition has been reported by C. cyminum and clove oil (Packiavathy et al., 


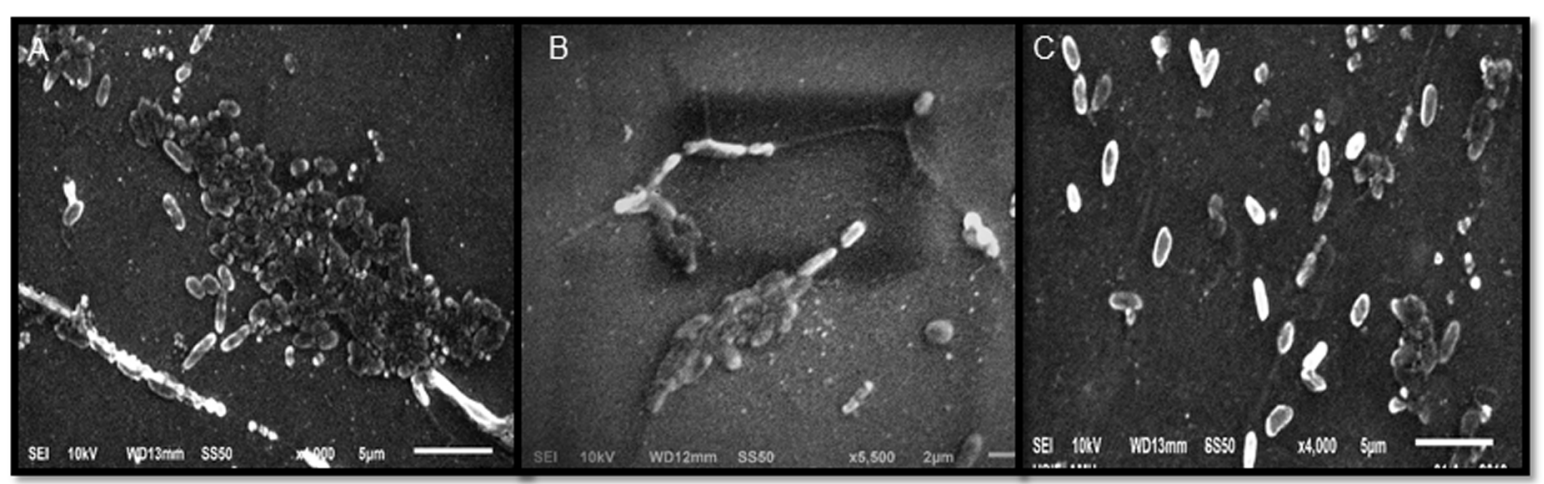

FIGURE 2 | Scanning electron microscopic (SEM) images for inhibition of biofilm of Pseudomonas aeruginosa PA01 at Sub minimum inhibitory concentrations. Images shown the effect on biofilm formation at $400 \mu \mathrm{g} / \mathrm{ml}$ (B) and $800 \mu \mathrm{g} / \mathrm{ml}$ (C) concentration of Mangifera indica (methanol) extract compared to control (A).

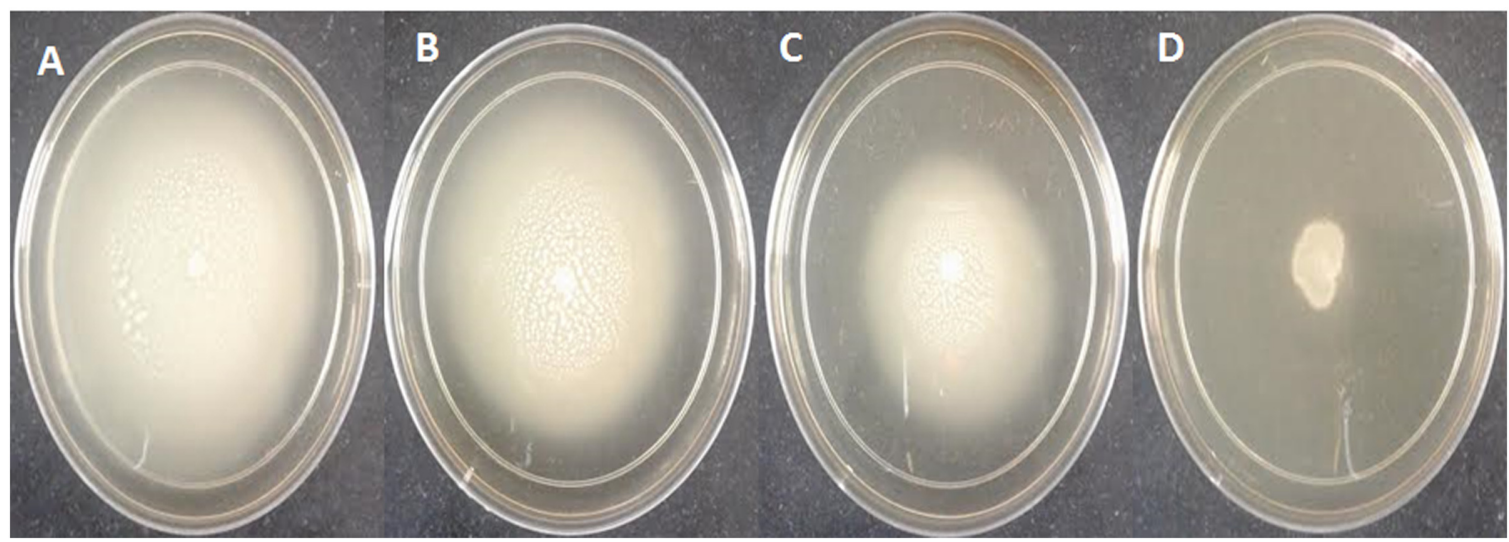

FIGURE 3 | Inhibition of swarming motility in P. aeruginosa PAO1 by sub-MICs of methanol extract of $M$. indica (leaf), (A) Untreated control; (B) $200 \mu \mathrm{g} / \mathrm{ml} ;$ (C) $400 \mu \mathrm{g} / \mathrm{ml}$; (D) $800 \mu \mathrm{g} / \mathrm{ml}$.

TABLE 3 | Effect of Mangifera indica leaf extract on inhibition of QS regulated virulence factors in Aeromonas hydrophila WAF-38.

\begin{tabular}{llll}
\hline Concentration $(\boldsymbol{\mu g} / \mathbf{m l})$ & \multicolumn{1}{c}{ Total protease $^{\mathbf{a}}$} & EPS production $^{\mathbf{b}}$ & Biofilm formation $^{\mathbf{c}}$ \\
\hline Control & $0.589 \pm 0.051$ & $0.748 \pm 0.021$ & $0.226 \pm 0.006$ \\
125 & $0.271 \pm 0.015(53.9)^{*}$ & $0.661 \pm 0.027(11.6)$ & $0.099 \pm 0.004(56.1)^{*}$ \\
250 & $0.223 \pm 0.006(62.1)^{*}$ & $0.434 \pm 0.009(41.9)^{*}$ & $0.087 \pm 0.009(61.5)^{*}$ \\
500 & $0.200 \pm 0.010(66.0)^{* *}$ & $0.357 \pm 0.005(52.2)^{*}$ & $0.054 \pm 0.006(76.1)^{* *}$ \\
1000 & $0.182 \pm 0.004(69.1)^{* *}$ & $0.306 \pm 0.018(59.0)^{*}$ & $0.040 \pm 0.003(82.3)^{* * *}$ \\
\hline
\end{tabular}

a Total protease activity is expressed as the absorbance at $600 \mathrm{~nm}$. ${ }^{\mathrm{b}}$ EPS production is expressed as absorbance at $480 \mathrm{~nm}$. ${ }^{\mathrm{c}}$ Biofilm formation is expressed at $470 \mathrm{~nm}$ after incubation with crystal violet. Data represent mean and standard deviation of three independent experiments. Values in parentheses indicate percent reduction over control. ${ }^{*} p \leq 0.05,{ }^{* *} p \leq 0.005,{ }^{* * *} p \leq 0.001$

2012; Husain et al., 2013). C. violaceum was used as the model for screening QS inhibitors because of the easy detection of the purple-colored pigmentation (violacein) in the indicator organism. Therefore, based on the violacein inhibition and lack of growth inhibition of the indicator organism CVO26, the methanol fraction was found the most active and thus further tested against $P$. aeruginosa $\mathrm{PAO} 1$ and A. hydrophila WAF38 to assess broad spectrum anti-QS activity because these organisms involve a different QS system than CVO26.
Pseudomonas aeruginosa secretes a range of QS-regulated virulence factors including elastase, protease and chitinase (Adonizio et al., 2008). The bacterial hydrolytic enzymes such as elastase and protease are known to affect the host cell proteins in the infected tissues and facilitate bacterial invasion and growth. In the present investigation, preincubation with the extract produced concentration-dependent inhibition of elastase and protease production. These data corroborated with the literature where, elastase activity, total proteolytic and chitinase activity 


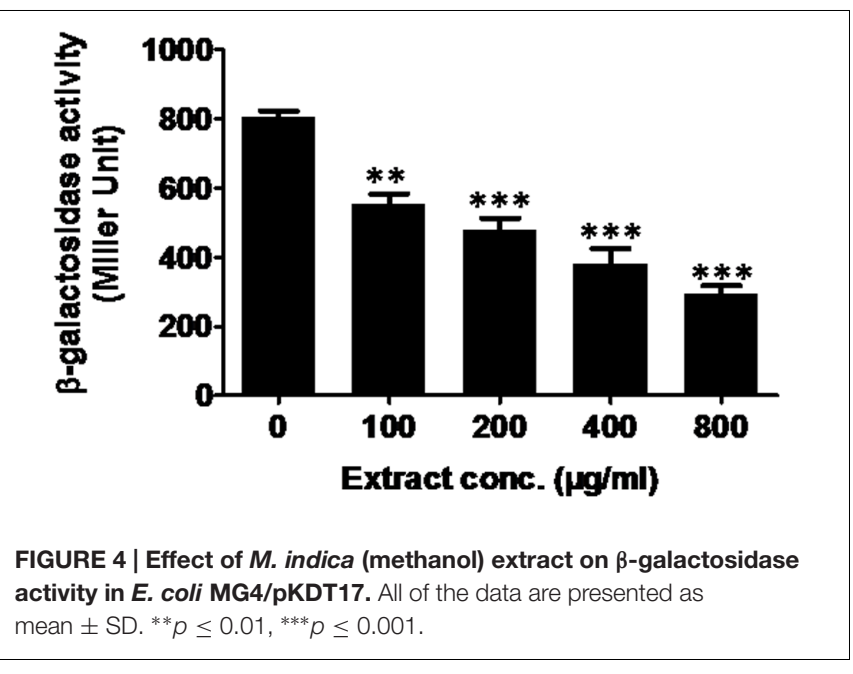

of $P$. aeruginosa was decreased to varying levels (10-90\%) by plant extracts and essential oils (Vattem et al., 2007; Husain and Ahmad, 2013b). Pyocyanin is another important virulence factor produced under QS-regulation. The role of pyocyanin is well documented in pathogenesis especially in cystic fibrosis (Winstanley and Fothergill, 2009). A significant dose-dependent decrease $(p \leq 0.001)$ was observed with ML extract in all strains, being maximum in PAO1 (88.8\%). Similar reduction in pyocyanin production was recorded in extracts of Terminalia chebula (Sarabhai et al., 2013).

Quorum sensing mediated by AHLs are known to play significant role in biofilm formation. We found that the ML extract at Sub-MICs inhibited the biofilm biomass significantly $(P \leq 0.005)$ with no significant growth inhibition on PAO1. Sandasi et al. (2010) showed that surface adhesion followed by microcolony formation is promoted by surface conditioning.

Scanning electron microscopy images revealed ML extract efficiently reduced biofilm formed by bacteria which have further

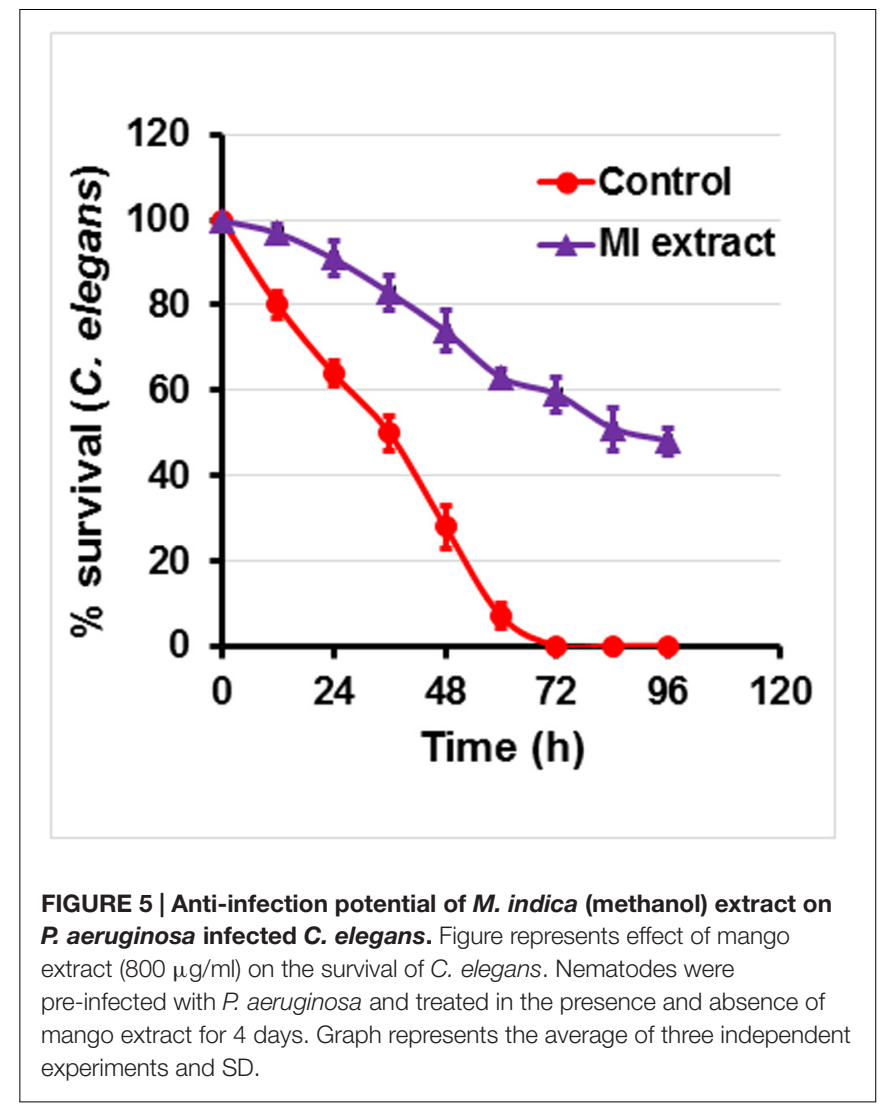

demonstrated that $\mathrm{ML}$ extract treatment reduces the biofilm strength. The possible interference in biofilm formation might be due to reducing surface adhesion or subsequent step of biofilm formation. The extract inhibiting QS is expected to adversely affect biofilm forming capacity (De Kievit et al., 2001). The results obtained in our study are in agreement with activity of extracts of C. viminalis, Quercus virginiana, Tetrazygia bicolor (Adonizio

TABLE 4 | Phytochemicals of Mangifera indica extract as identified by GC-MS analysis.

\begin{tabular}{|c|c|c|c|}
\hline Peak no. & Components & Retention time & Area (\%) \\
\hline 1. & 1,3,5-Triazine-2,4,6-triamine & 3.66 & 6.66 \\
\hline 2. & 1,2,3-Propanetriol, monoacetate & 3.88 & 1.40 \\
\hline 3. & 4H-Pyran-4-one, 2,3-dihydro-3,5-dihydroxy-6-methyl & 4.60 & 8.48 \\
\hline 4. & 2-Furancarboxaldehyde, 5-(hydroxymethyl) & 5.90 & 4.72 \\
\hline 5. & 1,2,3-Benzenetriol & 8.42 & 15.60 \\
\hline 6. & Benzoic acid, 4-hydroxy & 10.36 & 12.09 \\
\hline 7. & 1,2,3,4,5,6,7,8-Octahydro-2-naphthol, 4-methylene-2,5,5-trimethyl & 11.61 & 1.03 \\
\hline 8. & Tetradecanoic acid & 12.63 & 1.72 \\
\hline 9. & Pluchidiol & 13.17 & 1.19 \\
\hline 10. & Hexadecanoic acid, methyl ester & 14.28 & 2.58 \\
\hline 11. & n-Hexadecanoic acid & 14.70 & 9.96 \\
\hline 12. & 9,12,15-Octadecatrienoic acid, methyl ester & 15.99 & 1.71 \\
\hline 13. & Phytol & 16.11 & 2.24 \\
\hline 14. & 9,12,15-Octadecatrienoic acid, (Z,Z,Z)- & 16.40 & 6.22 \\
\hline 15. & Stigmast-5-en-3-ol, (3.beta.)- & 29.47 & 2.32 \\
\hline 16. & Lupeol & 30.26 & 1.07 \\
\hline
\end{tabular}


A

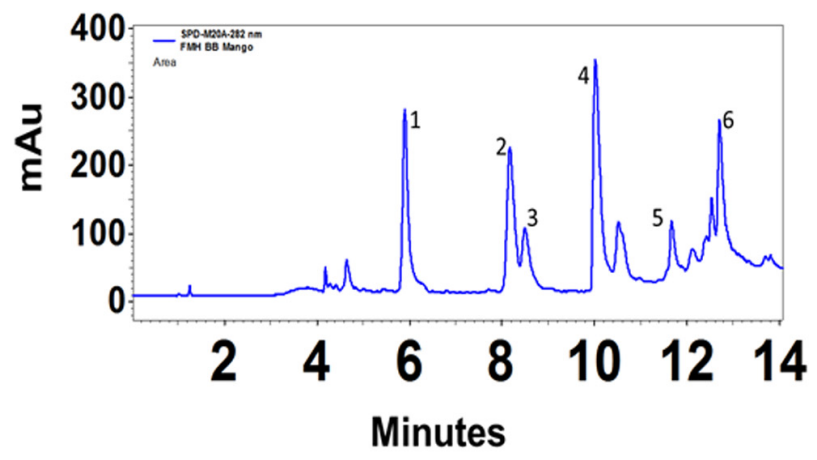

B

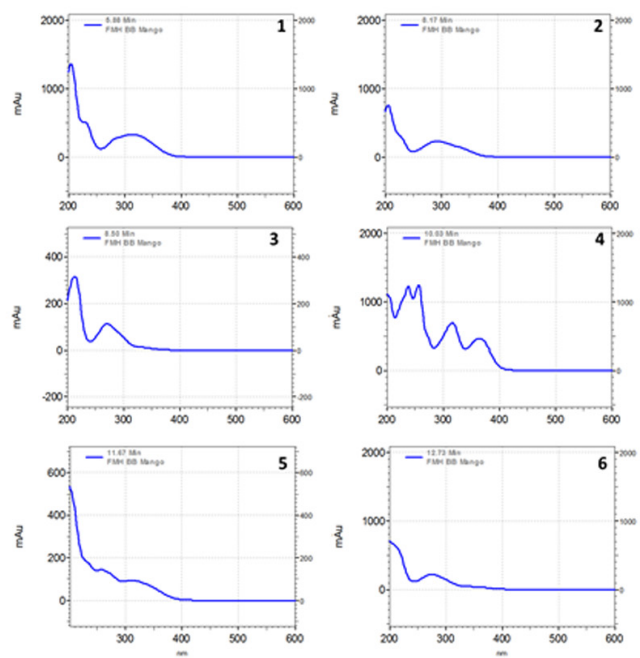

FIGURE 6 | HPLC profile of Mangifera indica (methanol) leaf extract. Twenty microliter of extracts $(1 \mathrm{mg} / \mathrm{ml}$ ) were injected and analyzed using photo diode array detector on a C18 $(250 \mathrm{~mm} \times 4.6 \mathrm{~mm} \mathrm{ID} \times 5 \mu \mathrm{m})$ reverse phase column in a gradient of $3.5 \%$ aqueous phosphoric acid and acetonitrile. Chromatograms in (A) represent various polyphenolics detected at $280 \mathrm{~nm}$. Chromatograms in the (B) represent analysis of different peaks as indicated in (A) in the range of 200-600 nm. mAu, milli absorbance units. For clarity of data, $y$-axis scales are different.

et al., 2008), Lagerstroemia speciosa (Singh et al., 2012), and Sclerocarya birrea (Sarkar et al., 2014).

Factors closely associated with biofilm formation of $P$. aeruginosa like swarming motility and EPS production were also evaluated in this study. Production of EPS is a prerequisite for the biofilm maturation (Watnick and Kolter, 1999), a QS regulated trait (Vu et al., 2009). Therefore, reduction in EPS production is due to QS interference by plant extracts (Abraham et al., 2011). It is hoped that plant extract significantly $(p \leq 0.05)$ reducing EPS will possibly reduce the resistance level of the pathogen in sessile mode. Treatment of PAO1 by plant extract reduces the EPS production. A dose-dependent decrease was observed in swarming motility of PAO1. It has been shown that flagellar-driven motility is required for surface attachment initiation in biofilm development (Pratt and Kolter, 1998). Therefore, inhibition in flagellar synthesis by the extracts would facilitate the reduced swarming migration. Thus, these extracts might have indirectly impacted biofilm formation by pathogens at least in part by disturbing AHL-mediated QS-system.

Virulence factors like exo-proteases production, EPS production and the biofilm formation are regulated by ahyRI QS system (Williams, 2007). ML extract demonstrated dosedependent significant $(p \leq 0.005)$ reduction in the total protease and EPS production by A. hydrophila WAF38. Biofilm formation was also inhibited in a concentration-dependent manner by sub-MICs of extracts tested. The data obtained in our study for protease and biofilm inhibition indicated that the extract is potentially acting on the AhyRI system rendering the production of C4-HSL impaired. Similar findings against Aeromonas sp. were reported with chestnut honey and its extracts at $0.2 \mathrm{~g} / \mathrm{ml}$ concentration, inhibiting biofilm up to $61 \%$ over control (Truchado et al., 2009).
The addition of $\mathrm{ML}$ extract decreased $\beta$-galactosidase luminescence in E. coli MG4/pKDT17 significantly ( $p \leq 0.005)$ at sub-MICs. The results of the assay demonstrate reduction in AHL production under the effect of plant extract inhibits las-controlled transcription. It has been demonstrated that AHL is needed in combination with the LasR to achieve the maximal activation of the lasB gene, (Passador et al., 1993). Therefore, a critical global regulatory system is formed by LasR and AHL for the expression of $P$. aeruginosa virulence factors. The dependence of lasB-lacZ expression on AHL concentration has been reported (Pearson et al., 1994). Therefore, it is evident that reduction in the $\beta$-galactosidase activity in this study relates to reduce AHL levels through interference of $l a s B$ gene expression. Our results corroborates with the observations on $L$. speciosa fruit extract (Singh et al., 2012) and eugenol (Zhou et al., 2013).

Further, observation on the protection of $C$. elegans infected with $P$. aeruginosa $\mathrm{PAO} 1$ in the presence of ML extract provided a proof of the anti-virulence property. Our findings are in support of earlier works, which demonstrated similar activity of garlic extracts (Rasmussen and Givskov, 2006).

Mangifera indica $\mathrm{L}$ is rich in polyphenolic content and GC-MS analysis further confirmed the presence of an array of compounds. Pyrogallol was detected as the major compound which is known to exhibit antagonism against the QS signaling molecule AI-2 and virulence factors of Vibrio sp. (Brackman et al., 2008; Ni et al., 2008).

Inhibition of multiple traits regulated by QS by ML extract indicated its broad-spectrum activity through the QS interference possibly at multiple targets. Various compounds present in the extract might also influence QS by indirectly acting on the other primary target linked to QS functioning. The compounds like trifluoromethyl ketones, phenothiazine and phenothiazine 
thioridazine that inhibit proton motive force linked activities such as motility of Gram negative bacteria, and also inhibitor of the proton motive force-dependent efflux pump system of bacteria and QS system (Varga et al., 2012). The possible role of various synthetic and natural compounds has been reported as efflux pump inhibitor of Gram negative bacteria and QS interference (Amaral and Molnar, 2012). Therefore, presence of such compounds in the plant extracts may also influence the anti-QS activity through the efflux pump inhibition and needs further investigation. On the other hand, pyrogallol detected in this study is known to inhibit QS through generation of $\mathrm{H}_{2} \mathrm{O}_{2}$ that somehow interfere with the expression of bioluminescence in Vibrio (Defoirdt et al., 2013).

Our data indicated that ML extracts and its active constituents as a potential candidate for exploiting as anti-infective agent in modern phytomedicine. Further identifying and exploring active compounds as novel anti-QS agent that effectively inhibit virulence and demonstrate the therapeutic utility against drug resistant bacteria are needed.

\section{AUTHOR CONTRIBUTIONS}

FMH carried out all screening experiments and characterization of their anti QS properties. FA designed and carried out UPLC

\section{REFERENCES}

Abraham, S. V., Palani, A., Ramaswamy, B. R., Shunmugiah, K. P., and Arumugam, V. R. (2011). Antiquorum sensing and antibiofilm potential of Capparis spinosa. Arch. Med. Res. 42, 658-668. doi: 10.1016/j.arcmed.2011.12.002

Adonizio, A., Kong, K. F., and Mathee, K. (2008). Inhibition of quorum sensing-controlled virulence factor production in Pseudomonas aeruginosa by south Florida plant extracts. Antimicrob. Agents Chemother. 52, 198-203. doi: 10.1128/AAC.00612-07

Ahmad, I., and Aqil, F. (2007). In vitro efficacy of bioactive extracts of 15 medicinal plants against ES beta L-producing multidrug-resistant enteric bacteria. Microbiol. Res. 162, 264-275. doi: 10.1016/j.micres.2006.06.010

Alhede, M., Bjarnsholt, T., Jensen, P. O., Phipps, R. K., Moser, C., Christophersen, L., et al. (2009). Pseudomonas aeruginosa recognizes and responds aggressively to the presence of polymorphonuclear leukocytes. Microbiology 155, 3500-3508. doi: 10.1099/mic.0.031443-0

Amaral, L., and Molnar, J. (2012). Inhibitors of efflux pumps of Gram-negative bacteria inhibit Quorum Sensing. Open J. Pharmacol. 2, 2-15.

Annapoorani, A., Kalpana, B., Musthafa, K. S., Pandian, S. K., and Ravi, A. V. (2013). Antipathogenic potential of Rhizophora spp. against the quorum sensing mediated virulence factors production in drug resistant Pseudomonas aeruginosa. Phytomedicine 20, 956-963. doi: 10.1016/j.phymed.2013.04.011

Aqil, F., Vadhanam, M. V., Jeyabalan, J., Cai, J., Singh, I. P., and Gupta, R. C. (2014). Detection of anthocyanins/anthocyanidins in animal tissues. J. Agric. Food Chem. 62, 3912-3918. doi: 10.1021/jf500467b

Bhowmik, T., and Marth, E. H. (1990). $\beta$-Galactosidase of Pediococcus species: induction, purification and partial characterization. Appl. Microbiol. Biotechnol. 33, 317-323. doi: 10.1007/BF00164529

Blosser, R. S., and Gray, K. M. (2000). Extraction of violacein from Chromobacterium violaceum provides a new quantitative bioassay for $N$-acyl homoserine lactone autoinducers. J. Microbiol. Methods 40, 47-55. doi: 10.1016/ S0167-7012(99)00136-0

Brackman, G., Cos, P., Maes, L., Nelis, H. J., and Coenye, T. (2011). Quorum sensing inhibitors increase the susceptibility of bacterial biofilms to antibiotics in vitro and in vivo. Antimicrob. Agents Chemother. 55, 2655-2661. doi: 10.1128/AAC.00045-11 studied. AA-t, HHA, and IMA contributed to phytochemical analysis of GC result and contributed in the writing and revision of the manuscript. IA designed and supervised all the work. All authors read and approved the final version of the manuscript.

\section{ACKNOWLEDGMENTS}

The authors would like to extend their thanks to the Deanship of Scientific Research, College of Science, King Saud University, Riyadh, KSA. FMH is thankful to DST. New Delhi for providding INSPIRE fellowship. We are also thankful to Prof. Robert J. C. McLean (University of Texas, USA), Prof. Deborah A. Hogan (Dartmouth Medical School, USA), and Prof. Thomas K. Wood (Pennsylvania State University, USA) for providing QS bioreporter strains. Prof. Qudsia Tahsin, Department of Zoology, AMU, Aligarh for C. elegans study support.

\section{SUPPLEMENTARY MATERIAL}

The Supplementary Material for this article can be found online at: http://journal.frontiersin.org/article/10.3389/fmicb. 2017.00727/full\#supplementary-material

Brackman, G., Defoirdt, T., Miyamoto, C., Bossier, P., Van Calenbergh, S., Nelis, H., et al. (2008). Cinnamaldehyde and cinnamaldehyde derivatives reduce virulence in Vibrio spp. by decreasing the DNA-binding activity of the quorum sensing response regulator LuxR. BMC Microbiol. 8:149. doi: 10.1186/14712180-8-149

Dandekar, A. A., Chugani, S., and Greenberg, E. P. (2012). Bacterial quorum sensing and metabolic incentives to cooperate. Science 338, 264-266. doi: 10.1126/science.1227289

De Kievit, T. R., Gillis, R., Marx, S., Brown, C., and Iglewski, B. H. (2001). Quorumsensing genes in Pseudomonas aeruginosa biofilms: their role and expression patterns. Appl. Environ. Microbiol. 67, 1865-1873. doi: 10.1128/AEM.67.4. 1865-1873.2001

Defoirdt, T., Pande, G. S. J., Baruah, K., and Bossier, P. (2013). The apparent quorum-sensing inhibitory activity of pyrogallol is a side effect of peroxide production. Antimicrob. Agents Chemother. 57, 2870-2873. doi: 10.1128/AAC. 00401-13

Dubois, M., Gilles, K., Hamilton, J. K., Rebers, P. A., and Smith, F. (1951). A colorimetric method for the determination of sugars. Nature 168:167. doi: 10.1038/168167a0

Essar, D. W., Eberly, L., Hadero, A., and Crawford, I. P. (1990). Identification and characterization of genes for a second anthranilate synthase in Pseudomonas aeruginosa: interchangeability of the two anthranilate synthases and evolutionary implications. J. Bacteriol. 172, 884-900. doi: 10.1128/jb.172.2. 884-900.1990

Fuqua, C., Parsek, M. R., and Greenberg, E. P. (2001). Regulation of gene expression by cell-to-cell communication: acyl-homoserine lactone quorum sensing. Annu. Rev. Genet. 35, 439-468. doi: 10.1146/annurev.genet.35.102401. 090913

Ghosh, R., Tiwary, B. K., Kumar, A., and Chakraborty, R. (2014). Guava leaf extract inhibits quorum-sensing and Chromobacterium violaceum induced lysis of human hepatoma cells: whole transcriptome analysis reveals differential gene expression. PLoS ONE 9:e107703. doi: 10.1371/journal.pone.01 07703

Harjai, K., Kumar, R., and Singh, S. (2010). Garlic blocks quorum sensing and attenuates the virulence of Pseudomonas aeruginosa. FEMS Immunol. Med. Microbiol. 58, 161-168. doi: 10.1111/j.1574-695X.2009.00614.x 
Hentzer, M., and Givskov, M. (2003). Pharmacological inhibition of quorum sensing for the treatment of chronic bacterial infections. J. Clin. Invest. 112, 1300-1307. doi: 10.1172/JCI20074

Husain, F. M., and Ahmad, I. (2013a). Doxycycline interferes with quorum sensing-mediated virulence factors and biofilm formation in gram-negative bacteria. World J. Microbiol. Biotechnol. 29, 949-957. doi: 10.1007/s11274-0131252-1

Husain, F. M., and Ahmad, I. (2013b). Quorum sensing inhibitors from natural products as potential novel antiinfective agents. Drug Future 38, 691-706. doi: 10.1358/dof.2013.038.10.2025393

Husain, F. M., Ahmad, I., Asif, M., and Tahseen, Q. (2013). Influence of clove oil on certain quorum-sensing-regulated functions and biofilm of Pseudomonas aeruginosa and Aeromonas hydrophila. J. Biosci. 38, 835-844. doi: 10.1007/ s12038-013-9385-9

Huston, A. L., Methe, B., and Deming, J. W. (2004). Purification, characterization, and sequencing of an extracellular cold-active aminopeptidase produced by marine psychrophile Colwellia psychrerythraea strain 34H. Appl. Environ. Microbiol. 70, 3321-3328. doi: 10.1128/AEM.70.6.3321-3328.2004

Jaisi, D. P., Dong, H. L., Kim, J., He, Z. Q., and Morton, J. P. (2007). Nontronite particle aggregation induced by microbial Fe(III) reduction and exopolysaccharide production. Clay Clay Miner. 55, 96-107. doi: 10.1346/ CCMN.2007.0550108

Jimenez, P. N., Koch, G., Thompson, J. A., Xavier, K. B., Cool, R. H., and Quax, W. J. (2012). The multiple signaling systems regulating virulence in Pseudomonas aeruginosa. Microbiol. Mol. Biol. Rev. 76, 46-65. doi: 10.1128/MMBR.05007-11

Kalia, V. C. (2013). Quorum sensing inhibitors: an overview. Biotechnol. Adv. 31, 224-245. doi: 10.1016/j.biotechadv.2012.10.004

Kessler, E., Safrin, M., Olson, J. C., and Ohman, D. E. (1993). Secreted LasA of Pseudomonas aeruginosa is a staphylolytic protease. J. Biol. Chem. 268, 7503-7508.

MacPherson, D. W., Gushulak, B. D., Baine, W. B., Bala, S., Gubbins, P. O., Holtom, P., et al. (2009). Population mobility, globalization, and antimicrobial drug resistance. Emerg. Infect. Dis. 15, 1727-1732. doi: 10.3201/eid1511.090419

McKnight, S. L., Iglewski, B. H., and Pesci, E. C. (2000). The Pseudomonas quinolone signal regulates rhl quorum sensing in Pseudomonas aeruginosa. J. Bacteriol. 182, 2702-2708. doi: 10.1128/JB.182.10.2702-2708.2000

McLean, R. J., Whiteley, M., Stickler, D. J., and Fuqua, W. C. (1997). Evidence of autoinducer activity in naturally occurring biofilms. FEMS Microbiol. Lett. 154, 259-263. doi: 10.1111/j.1574-6968.1997.tb12653.x

McLean, R. J. C., Pierson, L. S., and Fuqua, C. (2004). A simple screening protocol for the identification of quorum signal antagonists. J. Microbiol. Methods 58, 351-360. doi: 10.1016/j.mimet.2004.04.016

Musthafa, K. S., Balamurugan, K., Pandian, S. K., and Ravi, A. V. (2012). 2,5-Piperazinedione inhibits quorum sensing-dependent factor production in Pseudomonas aeruginosa PAO1. J. Basic Microbiol. 52, 679-686. doi: 10.1002/ jobm.201100292

Musthafa, K. S., Ravi, A. V., Annapoorani, A., Packiavathy, I. S. V., and Pandian, S. K. (2010). Evaluation of anti-quorum-sensing activity of edible plants and fruits through inhibition of the N-Acyl-homoserine lactone system in Chromobacterium violaceum and Pseudomonas aeruginosa. Chemotherapy 56, 333-339. doi: 10.1159/000320185

Ni, N. T., Choudhary, G., Li, M. Y., and Wang, B. H. (2008). Pyrogallol and its analogs can antagonize bacterial quorum sensing in Vibrio harveyi. Bioorg. Med. Chem. Lett. 18, 1567-1572. doi: 10.1016/j.bmcl.2008.01.081

O’Toole, G. A., and Kolter, R. (1998). Initiation of biofilm formation in Pseudomonas fluorescens WCS365 proceeds via multiple, convergent signalling pathways: a genetic analysis. Mol. Microbiol. 28, 449-461. doi: 10.1046/j.13652958.1998.00797.x

Packiavathy, I. A. S. V., Agilandeswari, P., Musthafa, K. S., Pandian, S. K., and Ravi, A. V. (2012). Antibiofilm and quorum sensing inhibitory potential of Cuminum cyminum and its secondary metabolite methyl eugenol against Gram negative bacterial pathogens. Food Res. Int. 45, 85-92. doi: 10.1016/j.foodres.2011.10.022

Passador, L., Cook, J. M., Gambello, M. J., Rust, L., and Iglewski, B. H. (1993). Expression of Pseudomonas aeruginosa virulence genes requires cell-to-cell communication. Science 260, 1127-1130. doi: 10.1126/science.8493556

Pearson, J. P., Gray, K. M., Passador, L., Tucker, K. D., Eberhard, A., Iglewski, B. H., et al. (1994). Structure of the autoinducer required for expression of
Pseudomonas aeruginosa virulence genes. Proc. Natl. Acad. Sci. U.S.A. 91, 197-201. doi: 10.1073/pnas.91.1.197

Pratt, L. A., and Kolter, R. (1998). Genetic analysis of Escherichia coli biofilm formation: roles of flagella, motility, chemotaxis and type I pili. Mol. Microbiol. 30, 285-293. doi: 10.1046/j.1365-2958.1998.01061.x

Rasmussen, T. B., and Givskov, M. (2006). Quorum sensing inhibitors: a bargain of effects. Microbiology 152, 895-904. doi: 10.1099/mic.0.28601-0

Rumbaugh, K. P., Trivedi, U., Watters, C., Burton-Chellew, M. N., Diggle, S. P., and West, S. A. (2012). Kin selection, quorum sensing and virulence in pathogenic bacteria. Proc. Biol. Sci. 279, 3584-3588. doi: 10.1098/rspb.2012.0843

Sandasi, M., Leonard, C. M., and Viljoen, A. M. (2010). The in vitro antibiofilm activity of selected culinary herbs and medicinal plants against Listeria monocytogenes. Lett. Appl. Microbiol. 50, 30-35. doi: 10.1111/j.1472-765X.2009. 02747.x

Sarabhai, S., Sharma, P., and Capalash, N. (2013). Ellagic acid derivatives from Terminalia chebula Retz. downregulate the expression of quorum sensing genes to attenuate Pseudomonas aeruginosa PAO1 virulence. PLoS ONE 8:e53441. doi: 10.1371/journal.pone.0053441

Sarkar, R., Chaudhary, S. K., Sharma, A., Yadav, K. K., Nema, N. K., Sekhoacha, M., et al. (2014). Anti-biofilm activity of Marula - a study with the standardized bark extract. J. Ethnopharmacol. 154, 170-175. doi: 10.1016/j.jep.2014. 03.067

Shah, K. A., Patel, M. B., Patel, R. J., and Parmar, P. K. (2010). Mangifera indica (mango). Pharmacog. Rev. 4, 42-48. doi: 10.4103/0973-7847.65325

Singh, B. N., Singh, H. B., Singh, A., Singh, B. R., Mishra, A., and Nautiyal, C. S. (2012). Lagerstroemia speciosa fruit extract modulates quorum sensingcontrolled virulence factor production and biofilm formation in Pseudomonas aeruginosa. Microbiology 158, 529-538. doi: 10.1099/mic.0.052985-0

Smith, R. S., and Iglewski, B. H. (2003). P. aeruginosa quorum-sensing systems and virulence. Curr. Opin. Microbiol. 6, 56-60. doi: 10.1016/S1369-5274(03)00008-0

Spanos, G. A., and Wrolstad, R. E. (1990). Influence of processing and storage on the phenolic composition of Thompson Seedless grape juice. J. Agric. Food Chem. 38, 1565-1571. doi: 10.1021/jf00097a030

Truchado, P., Gil-Izquierdo, A., Tomas-Barberan, F., and Allende, A. (2009). Inhibition by chestnut honey of N-Acyl-L-homoserine lactones and biofilm formation in Erwinia carotovora, Yersinia enterocolitica, and Aeromonas hydrophila. J. Agric. Food Chem. 57, 11186-11193. doi: 10.1021/jf9029139

Van Delden, C., and Iglewski, B. H. (1998). Cell-to-cell signaling and Pseudomonas aeruginosa infections. Emerg. Infect. Dis. 4, 551-560.

Varga, Z. G., Armada, A., Cerca, P., Amaral, L., Mior Ahmad Subki, M. A., Savka, M. A., et al. (2012). Inhibition of quorum sensing and efflux pump system by trifluoromethyl ketone proton pump inhibitors. In Vivo. 26, 277-285.

Vattem, D. A., Mihalik, K., Crixell, S. H., and McLean, R. J. C. (2007). Dietary phytochemicals as quorum sensing inhibitors. Fitoterapia 78, 302-310. doi: 10.1016/j.fitote.2007.03.009

Vu, B., Chen, M., Crawford, R. J., and Ivanova, E. P. (2009). Bacterial extracellular polysaccharides involved in biofilm formation. Molecules 14, 2535-2554. doi: 10.3390/molecules14072535

Wang, W. Z., Sato, T., Ito, S., Kato, N., Morohoshi, T., and Ikeda, T. (2009). Inhibition of quorum sensing in gram-negative bacteria using AHL analogues and modified cyclodextrins. J. Biosci. Bioeng. 108, S38-S38. doi: 10.1016/j.jbiosc. 2013.01.022

Watnick, P. I., and Kolter, R. (1999). Steps in the development of a Vibrio cholerae El Tor biofilm. Mol. Microbiol. 34, 586-595. doi: 10.1046/j.1365-2958.1999. 01624.x

Williams, P. (2007). Quorum sensing, communication and cross-kingdom signalling in the bacterial world. Microbiology 153, 3923-3938. doi: 10.1099/ mic.0.2007/012856-0

Winstanley, C., and Fothergill, J. L. (2009). The role of quorum sensing in chronic cystic fibrosis Pseudomonas aeruginosa infections. FEMS Microbiol. Lett. 290, 1-9. doi: 10.1111/j.1574-6968.2008.01394.x

Zahin, M., Ahmad, I., and Aqil, F. (2016). Antioxidant and antimutagenic potential of Psidium guajava leaf extracts. ıDrug Chem. Toxicol. 2, 1-8. doi: 10.1080/ 01480545.2016.1188397

Zahin, M., Aqil, F., Husain, F. M., and Ahmad, I. (2013). Antioxidant capacity and antimutagenic potential of Murraya koenigii. Biomed. Res. Int. 2013:263509. doi: $10.1155 / 2013 / 263509$ 
Zahin, M., Hasan, S., Aqil, F., Khan, M. S. A., Husain, F. M., and Ahmad, I. (2010). Screening of certain medicinal plants from India for their anti-quorum sensing activity. Indian J. Exp. Biol. 48, 1219-1224.

Zhao, Z. G., Yan, S. S., Yu, Y. M., Mi, N., Zhang, L. X., Liu, J., et al. (2013). An aqueous extract of Yunnan baiyao inhibits the quorum-sensing-related virulence of Pseudomonas aeruginosa. J. Microbiol. 51, 207-212. doi: 10.1007/ s12275-013-2595-x

Zhou, L. M., Zheng, H. D., Tang, Y. D., Yu, W. G., and Gong, Q. H. (2013). Eugenol inhibits quorum sensing at sub-inhibitory concentrations. Biotechnol. Lett. 35, 631-637. doi: 10.1007/s10529-012$1126-\mathrm{x}$
Conflict of Interest Statement: The authors declare that the research was conducted in the absence of any commercial or financial relationships that could be construed as a potential conflict of interest.

Copyright (๑) 2017 Husain, Ahmad, Al-thubiani, Abulreesh, AlHazza and Aqil. This is an open-access article distributed under the terms of the Creative Commons Attribution License (CC BY). The use, distribution or reproduction in other forums is permitted, provided the original author(s) or licensor are credited and that the original publication in this journal is cited, in accordance with accepted academic practice. No use, distribution or reproduction is permitted which does not comply with these terms. 